\title{
Clinicoepidemiological and laboratory findings of COVID positive patients presenting to a tertiary care centre in South India: A retrospective analysis
}

\author{
Diya Biju $^{\text {a,*, Soumya Johnson }}{ }^{\mathrm{a}}$, Chithra Valsan ${ }^{\mathrm{b}}$, A.B Prasad ${ }^{\mathrm{c}}$, Praveenlal Kuttichira ${ }^{\mathrm{a}}$ \\ ${ }^{a}$ Jubilee Mission Medical College and Research Institute, Thrissur, Kerala, India \\ ${ }^{\mathrm{b}}$ Department of Microbiology, Jubilee Mission Medical College and Research Institute, Thrissur, Kerala, India \\ ${ }^{\mathrm{c}}$ Department of Economics and Statistics, Thrissur, India
}

\section{A R T I C L E I N F O}

\section{Keywords:}

COVID-19

SARS-CoV-2

Coronavirus

India

Kerala

Clinical characteristics

Symptomatic vs asymptomatic

Male vs female

Laboratory findings

Lymphocytopenia

Inflammatory markers

\begin{abstract}
A B S T R A C T
Background: SARS CoV2 continues to pose a threat to human race even after one year of its outset in China. Observational studies from across the world have shown huge disparity in the clinicoepidemiological and laboratory features of this disease. In this study we attempt to assess the clinical, epidemiological and laboratory parameters of COVID 19 positive patients in this geographic location.

Methods: This is a descriptive retrospective study of patients who were tested positive for SARS-CoV-2 at a tertiary care centre in central Kerala, India between July 16, 2020 and November 30, 2020. The clinicoepidemiological and laboratory parameters of the confirmed patients were collected from the laboratory and hospital records and analysed.

Results: A total of 1051 patients were tested positive during the study period. The mean age of the patients was 45.7 years \pm Standard Deviation (SD): 8.68; 51.76\% were male. Among them $658(62.61 \%)$ were symptomatic and $393(37.39 \%)$ were asymptomatic; males $(54.7 \%)$ were more symptomatic than females $(45.3 \%)$. The common presenting symptoms were fever (43.58\%), cough (21.50\%), myalgia or fatigue (10.28\%). Lymphocytopenia was more in males than females. Laboratory parameters such as Serum Ferritin, Alanine Transferase, Aspartate Transferase, Sodium level were elevated in males compared to female.

Conclusion: The common symptoms in our study could emphasize on identifying potential patients in this geographic area. Asymptomatic patients should be monitored and investigated for effective control of the disease. A knowledge about the disease presentation in each geographic area is important in planning the effective management strategies since the features are varied from place to place.
\end{abstract}

\section{Introduction}

On March 11, 2020, World Health Organization (WHO) has declared the Coronavirus Disease 2019 (COVID-19) outbreak as a global pandemic. ${ }^{1}$ The disease brought life to an unexpected standstill and continues to wreak havoc around the world. As of now there are over 91 million confirmed cases of COVID-19 including nearly 2 million deaths globally $^{2}$

The first case in India was reported on Jan 30, 2020, in Thrissur, Kerala from a student who returned from Wuhan, China. ${ }^{3}$ In February 2020, there was no significant rise in case. By the month of March there was a substantial increase in the number of positive cases due to increased travel from affected countries, ${ }^{4}$ gradually the disease spread across the whole country. India became the second most affected country in the world contributing to over 10 million confirmed cases and over 1 lakh deaths ${ }^{2}$

Understanding the clinical and epidemiological characteristics of the disease became an important step for effective detection and management of COVID-19. The clinical and epidemiological characteristics of COVID-19 were reported across the world. ${ }^{5-9}$ However most of these reports have variable characteristics suggesting the diversity and novelty of the disease across the world. Therefore, it is important to analyse the clinical and epidemiological characteristics in a local population for better management of the disease.

In this study we retrospectively analysed the clinical and epidemiological characteristics of patients diagnosed as COVID 19 positive by laboratory investigations in a tertiary care centre in South India. We also attempted to compare the disease characteristics in symptomatic and

\footnotetext{
* Corresponding author.

E-mail address: diyabiju98@gmail.com (D. Biju).
} 
asymptomatic patients.

\section{Methods}

\subsection{Data collection}

This is a descriptive retrospective study conducted in the department of Microbiology, Jubilee Mission Medical College, Thrissur, Kerala between July 16, 2020 and November 30, 2020. The centre is a 1700 bedded tertiary care centre which caters patients from three districts. All patients who were tested positive for SARS CoV2 during the study period were included in our study. Those who had indeterminate or inconclusive results were excluded from the study. The clinical, epidemiological and laboratory findings of these patients at the time of testing were collected from the laboratory and hospital registers as per the proforma available as supplementary data and analysed statistically.

The testing for COVID 19 was done in the molecular diagnostic laboratory of the Microbiology Department which is an ICMR approved and National Accreditation Board of Testing and Calibration Laboratories (NABL) accredited centre for COVID 19 testing. During the study period 17057 RTPCR and 12973 antigen test was done. All patients admitted in the hospital along with their bystander had to undergo Covid test irrespective of their signs and symptoms. The following categories of people had undergone testing in our centre during study period.

- Patients with signs and symptoms suggestive of COVID 19: 6453

- All patients admitted to the hospital:10575

- Patients posted for surgeries:450

- Bystanders of the patient:10952

- Contacts of the laboratory confirmed cases: 1250

- Travellers:350

Nasopharyngeal/oropharyngeal swabs were collected from the above groups as per the national and state guidelines for testing. The diagnosis was made by either COVID 19 Real Time-Polymerase Chain Reaction (RT-PCR) or Antigen tests abiding by these guidelines.

\subsection{Statistical analysis}

The categorical variables were expressed in frequency and percentage. The continuous variables were expressed in mean, Standard Deviation (SD) and median. The difference between categorical variables were analysed with Chi-square Test or Fisher exact Test. All statistical analysis was performed using Statistical Package for the Social Science (SPSS) software version 26.0.

\section{Results}

During the study period from July 16th to November 30th' 2020 a total of 1051 cases were tested positive for COVID 19 at our centre. Out of 1051 cases, 799 cases were confirmed by RT-PCR and 252 cases by Antigen test. We retrospectively analysed these 1051 confirmed cases of COVID-19. Out of 1051 cases, 800 cases were admitted in the hospital. Among 800 cases, 336 cases were category A, 356 cases were category B and 108 cases were category C. ${ }^{10}$ A total of 858 patients $(81.6 \%)$ were recovered, 91 cases were transferred, 63 were opted for home treatment and 39 patients $(3.71 \%)$ died in which $29(74.3 \%)$ were males. The clinical and demographic characteristics are shown in Table 1. Mean age of the patients were 45.7 years (Standard Deviation $S D=18.68$ ). Majority of the patients belonged to the age group 15-47 years (48.91\%). Out of 1051 patients, $658(62.61 \%)$ were symptomatic and 393(37.39\%) were asymptomatic. Males $544(51.76 \%)$ were more than the females.

The common presenting symptoms were fever (43.58\%), cough $(21.50 \%)$, myalgia or fatigue $(10.28 \%)$, sore throat $(9.99 \%)$, dyspnoea $(8.37 \%)$, headache $(6.18 \%)$. The less common symptoms include
Table 1

Clinical and epidemiological characteristics of COVID-19 patients.

\begin{tabular}{|c|c|c|}
\hline Parameters & $n=1051$ & $\%$ \\
\hline \multicolumn{3}{|l|}{ AGE(YEAR) } \\
\hline Mean \pm SD $^{\mathrm{a}}$ & $45.7 \pm 18.68$ & - \\
\hline Range & $0-93$ & - \\
\hline 0-14 (paediatric group) & 37 & 3.52 \\
\hline 15-47 (young group) & 514 & 48.91 \\
\hline 48-63 (middle age group) & 295 & 28.07 \\
\hline$\geq 64$ (elderly group) & 205 & 19.50 \\
\hline \multicolumn{3}{|l|}{ GENDER } \\
\hline Male & 544 & 51.76 \\
\hline Female & 507 & 48.24 \\
\hline \multicolumn{3}{|l|}{ PRESENCE OF SYMPTOMS } \\
\hline Symptomatic & 658 & 62.61 \\
\hline Asymptomatic & 393 & 37.39 \\
\hline \multicolumn{3}{|l|}{ SIGNS AND SYMPTOMS } \\
\hline Fever & 458 & 43.58 \\
\hline Cough & 226 & 21.50 \\
\hline Others & 167 & 15.89 \\
\hline Myalgia/Fatigue & 108 & 10.28 \\
\hline Sore throat & 105 & 9.99 \\
\hline Dyspnoea & 88 & 8.37 \\
\hline Headache & 65 & 6.18 \\
\hline Rhinitis & 35 & 3.33 \\
\hline Anosmia & 31 & 2.95 \\
\hline Loose stools & 28 & 2.66 \\
\hline Vomiting & 19 & 1.81 \\
\hline Abdominal pain & 15 & 1.43 \\
\hline
\end{tabular}

a Standard Deviation.

rhinitis, anosmia, loose stools, vomiting, dysphagia, altered mental state, haemoptysis, dysuria, sinusitis, syncope, giddiness, appetite loss etc (Table 1).

The laboratory blood investigations were done for $490(46.62 \%)$ patients (Table 2). The blood test results showed that $12.22 \%$ of patients had increased leukocyte count and $8.49 \%$ of patients had decreased leukocyte count. Neutrophilia was seen in $28.9 \%$ of patients and lymphopenia in $34.45 \%$ of patients. Varying degree of liver dysfunction with an increase in aspartate aminotransferase (52.52\%), alanine aminotransferase $(28.73 \%)$ and alkaline phosphatase $(10.83 \%)$ were seen. The sodium and potassium levels were decreased in $47.78 \%$ and $35.31 \%$ of patients respectively. Inflammatory markers like C-reactive protein is increased in $52.19 \%$ of patients while $41.73 \%$ had Serum ferritin above normal range. D-dimer, troponin and Lactate dehydrogenase were increased in majority of tested patients.

\subsection{Comparison of clinical laboratory parameters of symptomatic and asymptomatic patients (Table 3)}

There was significant difference in age and sex between symptomatic and asymptomatic patients. Males (54.7\%) were more symptomatic than females $(45.3 \%)(\mathrm{P}=0.013)$. Compared to asymptomatic patients, symptomatic patients were significantly older $(\mathrm{P}<0.01)$. The occurrence of leukocytosis and lymphopenia were found similar in both symptomatic and asymptomatic patients. Asymptomatic patients have more liver dysfunction with significant difference in Alkaline Phosphatase levels $(P=0.001)$. Asymptomatic patients have $16.9 \%$ of increased ALP while symptomatic patients have $8.1 \%$ increase. Reduced levels of sodium and potassium were found in symptomatic patients. CRP level were found to be significantly elevated in symptomatic patients than in asymptomatic patients with a $\mathrm{P}$ value of 0.001 .

\subsection{Comparison of clinical and laboratory parameters of male and female patients (Table 4)}

The Mean age \pm SD of male is $47.7 \pm 18.3$ while that of female is 43.7 \pm 18.7 years. Infected males are significantly older than females $(\mathrm{P}<$ 0.001). Among all signs and symptoms only cough shows significant 
Table 2

Laboratory findings of tested COVID-19 patients.

\begin{tabular}{|c|c|c|c|}
\hline Parameters & Total test done & $n$ & $\%$ \\
\hline \multicolumn{4}{|c|}{ Leukocyte count $\left(\mathrm{x} 10^{9} / \mathrm{L}\right)$} \\
\hline Normal & 483 & 383 & 79.3 \\
\hline Decreased & & 41 & 8.49 \\
\hline Increased & & 59 & 12.22 \\
\hline \multicolumn{4}{|c|}{ Neutrophil count (\%) } \\
\hline Normal & 481 & 327 & 67.98 \\
\hline Decreased & & 15 & 3.12 \\
\hline Increased & & 139 & 28.9 \\
\hline \multicolumn{4}{|c|}{ Lymphocyte count (\%) } \\
\hline Normal & 479 & 259 & 54.07 \\
\hline Decreased & & 165 & 34.45 \\
\hline Increased & & 55 & 11.48 \\
\hline \multicolumn{4}{|c|}{ Eosinophil count (\%) } \\
\hline Normal & 479 & 311 & 64.93 \\
\hline Decreased & & 158 & 32.99 \\
\hline \multicolumn{4}{|l|}{ AST $(\mathrm{U} / \mathrm{L})^{\mathrm{a}}$} \\
\hline Normal & 436 & 203 & 46.56 \\
\hline Increased & & 229 & 52.52 \\
\hline \multicolumn{4}{|l|}{$\operatorname{ALT}(\mathrm{U} / \mathrm{L})^{\mathrm{b}}$} \\
\hline Normal & 449 & 319 & 71.05 \\
\hline Increased & & 129 & 28.73 \\
\hline \multicolumn{4}{|l|}{$\operatorname{ALP}(\mathrm{U} / \mathrm{L})^{\mathrm{c}}$} \\
\hline Normal & 396 & 350 & 88.38 \\
\hline Increased & & 43 & 10.86 \\
\hline \multicolumn{4}{|c|}{ Serum protein $(\mathrm{g} / \mathrm{dl})$} \\
\hline Normal & 374 & 280 & 74.87 \\
\hline Increased & & 84 & 22.46 \\
\hline \multicolumn{4}{|c|}{ Potassium (meq/l) } \\
\hline Normal & 405 & 254 & 62.72 \\
\hline Decreased & & 143 & 35.31 \\
\hline \multicolumn{4}{|c|}{ Sodium (meq/l) } \\
\hline Normal & 406 & 209 & 51.48 \\
\hline Decreased & & 194 & 47.78 \\
\hline \multicolumn{4}{|c|}{$\mathrm{CRP}(\mathrm{mg} / \mathrm{dl})^{\mathrm{d}}$} \\
\hline Normal & 297 & 141 & 47.47 \\
\hline Increased & & 155 & 52.19 \\
\hline \multicolumn{4}{|c|}{ D-dimer (ng/ml) } \\
\hline Normal & 249 & 59 & 23.69 \\
\hline Decreased & & 48 & 19.28 \\
\hline Increased & & 142 & 57.03 \\
\hline \multicolumn{4}{|c|}{ Ferritin (ng/ml) } \\
\hline Normal & 139 & 78 & 56.12 \\
\hline Increased & & 58 & 41.73 \\
\hline \multicolumn{4}{|c|}{ Troponin (ng/ml) } \\
\hline Normal & 42 & 19 & 45.24 \\
\hline Increased & & 23 & 54.76 \\
\hline \multicolumn{4}{|l|}{$\mathrm{LDH}(\mathrm{U} / \mathrm{L})^{\mathrm{e}}$} \\
\hline Normal & 31 & 10 & 32.26 \\
\hline Increased & & 21 & 67.74 \\
\hline \multicolumn{4}{|c|}{ a Aspartate Aminotransferase. } \\
\hline \multicolumn{4}{|c|}{ b Alanine Aminotransferase. } \\
\hline \multicolumn{4}{|c|}{ c Alkaline Phosphatase. } \\
\hline \multicolumn{4}{|c|}{ d C Reactive Protein. } \\
\hline e Lactate D & & & \\
\hline
\end{tabular}

difference between male and female $(P=0.01)$. There is a high significant difference in lymphocyte count in males and females $(P=0.007)$. Lymphopenia is seen mainly in males than females. Laboratory parameters such as Serum Ferritin, Alanine Transferase, Aspartate Transferase, Sodium level shows significant difference in males and females. All of them were increased in males $(\mathrm{p}<0.05)$.

\section{Discussion}

Kerala was known for effective control and management of COVID$19^{11}$ hence the clinical and epidemiological characteristics of COVID-19 in Kerala are worth reporting.

The mean age of our patients is similar to the previously published reports in North India ${ }^{7,8}$ and lower compared to other countries reports, ${ }^{5,12,17}$ this may be due to the higher proportion of young population in India. The disease was more in males than females and was
Table 3

Comparison of symptomatic and asymptomatic COVID-19 patients.

\begin{tabular}{|c|c|c|c|c|}
\hline Variables & $\begin{array}{l}\text { Total } \\
\text { Case }\end{array}$ & $\begin{array}{l}\text { Symptomatic } n \\
(\%)\end{array}$ & $\begin{array}{l}\text { Asymptomatic } n \\
(\%)\end{array}$ & $P$ \\
\hline Sex & & & & .013 \\
\hline Male & 544 & $360(66.2)$ & $184(33.8)$ & \\
\hline Female & 507 & $298(58.8)$ & $209(41.2)$ & \\
\hline Age(year) & & & & .008 \\
\hline Mean \pm SD & $\begin{array}{l}45.7 \pm \\
18.6\end{array}$ & $47.2 \pm 18.3$ & $43.3 \pm 19.01$ & \\
\hline Age $\geq 64$ year & 204 & $139(68.13)$ & $65(31.87)$ & \\
\hline \multicolumn{5}{|l|}{ Laboratory parameter $^{a}$} \\
\hline Increased D-dimer & 14 & $104(57.1)$ & $38(56.7)$ & 0.42 \\
\hline Increased Ferritin & 58 & $45(43.7)$ & $13(36.1)$ & 0.27 \\
\hline Increased Troponin & 23 & $18(51.4)$ & $5(71.4)$ & 0.32 \\
\hline Increased $\mathrm{LDH}^{\mathrm{a}}$ & 21 & $14(63.3)$ & $7(77.8)$ & 0.43 \\
\hline Increased $\mathrm{CRP}^{\mathrm{b}}$ & 155 & $122(58.7)$ & $33(37.1)$ & 0.001 \\
\hline Leukocytopenia & 59 & 29(11.9) & 12(13) & 0.88 \\
\hline Neutrophilia & 139 & $101(30.8)$ & $38(24.8)$ & 0.40 \\
\hline Lymphocytopenia & 165 & $114(34.9)$ & $51(33.6)$ & 0.93 \\
\hline Increased $\mathrm{AST}^{\mathrm{C}}$ & 229 & $159(53.4)$ & $70(50.7)$ & 0.82 \\
\hline Increased $\mathrm{ALT}^{\mathrm{d}}$ & 129 & $92(30.2)$ & $37(25.7)$ & 0.41 \\
\hline Increased ALP & 43 & $22(8.1)$ & $21(16.9)$ & 0.001 \\
\hline $\begin{array}{l}\text { Decreased } \\
\text { Potassium }\end{array}$ & 143 & $106(38.4)$ & $37(28.7)$ & 0.053 \\
\hline Decreased Sodium & 143 & $137(49.6)$ & $57(43.8$ & 0.15 \\
\hline
\end{tabular}

\footnotetext{
a Lactate Dehydrogenase.

b C Reactive Protein.

c Aspartate Aminotransferase.

d Alanine Aminotransferase.

e Alkaline Phosphatase.
}

Table 4

Comparison of male and female COVID-19 patients.

\begin{tabular}{|c|c|c|c|}
\hline Variables & Male n(\%) & Female n(\%) & $P$ \\
\hline Mean age \pm SD & $47.7 \pm 18.3$ & $43.7 \pm 18.7$ & .001 \\
\hline \multicolumn{4}{|l|}{ Symptoms $^{a}$} \\
\hline Fever & $251(46.1)$ & $207(40.8)$ & .09 \\
\hline Cough & $134(24.6)$ & $92(18.1)$ & .01 \\
\hline Myalgia/Fatigue & $52(9.5)$ & $56(11.04)$ & .74 \\
\hline Sore throat & $45(11.8)$ & $60(8.3)$ & .06 \\
\hline Dyspnoea & $52(9.6)$ & $36(7.1)$ & .18 \\
\hline Headache & $28(5.1)$ & $37(7.3)$ & .14 \\
\hline \multicolumn{4}{|l|}{ Laboratory parameters $^{\mathrm{a}}$} \\
\hline Leukocytosis & $35(13.7)$ & $24(10.6)$ & .52 \\
\hline Lymphocytopenia & $103(40.6)$ & $64(27.6)$ & .007 \\
\hline Neutrophilia & $85(33.3)$ & $54(23.9)$ & .71 \\
\hline Eosinopenia & $90(35.6)$ & $68(30.1)$ & .20 \\
\hline Increased CRP ${ }^{a}$ & $94(57.3)$ & $61(45.9)$ & .07 \\
\hline Increased D-dimer & $78(60.5)$ & $64(53.3)$ & .52 \\
\hline Increased Ferritin & $47(54)$ & $11(21.2)$ & .001 \\
\hline 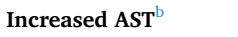 & $150(63.3)$ & $79(39.7)$ & .001 \\
\hline Increased ALT $^{\mathrm{C}}$ & $92(37.6)$ & $37(18.1)$ & .001 \\
\hline Decreased potassium & $66(30.7)$ & $77(40.5)$ & .11 \\
\hline Decreased sodium & $123(56.4)$ & $71(37.8)$ & .001 \\
\hline
\end{tabular}

a C Reactive Protein.

b Aspartate Aminotransferase.

c Alanine Aminotransferase.

consistent with previous studies from India and around the worls. ${ }^{5,7,12,16,19}$ The most common symptom was fever which is similar to the reports from North India, ${ }^{8}$ Saudi Arabia, ${ }^{16}$ China $^{5,9,14}$ but different from other studies around the world ${ }^{7,17,18}$ where cough is the most common symptom ${ }^{13}$

Higher levels of C Reactive Protein, D-Dimer, Troponin, Lactate dehydrogenase are seen in $52.19 \%, 57.03 \%, 54.73 \%, 67.74 \%$ of patients. According to the meta-analysis of 16 studies by Zeng et al. ${ }^{15}$ higher levels of inflammatory markers indicate severity of the disease. A positive correlation was observed between inflammatory markers and liver enzymes which is consistent with the previous report ${ }^{19}$ It is worth to note higher level of alkaline phosphatase are seen in $16.9 \%$ of 
asymptomatic patients compared to symptomatic patients (8.1\%). According to the study in Ranchi, Jharkhand liver injury is common in COVID-19 patients and alkaline phosphatase is one of the best indicator for Covid-19 induced liver injury. ${ }^{20}$ Our study shows that symptomatic patients belongs to older age group (Mean age \pm SD:47.2 \pm 18.1 ) compared to asymptomatic patients (Mean age \pm SD $43.3 \pm 19.1$ ) which is statistically significant(P:0.08). Laboratory findings such as D-Dimer, Ferritin, Troponin, Lactate Dehydrogenase is increased in $53.87 \%$ of symptomatic and $60.5 \%$ of asymptomatic patients.

Our study shows that males (66.2\%) are significantly more symptomatic compared to females (58.8\%) (P:0.01). According to a study by Scully et al. ${ }^{21}$ the difference in clinical parameters may be due to difference in sex chromosomes, epigenetic modification, transcriptional factors and sex steroid concentration that leads to varying degree of immune response in males and females. Increased levels of ALT were seen in $37.6 \%$ of males and $18.1 \%$ females $(P<0.0001)$ and increased level of AST were seen in $63.3 \%$ of males and $39.7 \%$ of females $(P<$ 0.000 ). Increase liver dysfunction enzymes may be due to higher expression of ACE2 receptors in males. ${ }^{22,23}$

The major limitation of our study was the retrospective study design and the insufficient data on clinical and laboratory profile of the patient. Severity and course of the disease could not be analysed as the data was taken laboratory registers which mainly came from test requisition accompanying samples. Initially all COVID 19 positive patients were admitted in the hospital as per the state guidelines regardless of severity of the disease. With the change in government protocol, only symptomatic patients were admitted and asymptomatic patients were given home treatment thus laboratory investigations done for asymptomatic patients became limited.

However, the data in this study permit to assess the early clinical and epidemiological characteristics of Covid-19 in South India.

The clinicoepidemiological characteristics of Covid-19 patients behaved differently in different geographical location. The common symptoms in our study could emphasize on identifying potential patients in this geographic area. Asymptomatic patients should be monitored and investigated for effective control of the disease. A knowledge about the disease presentation in each geographic area is important in planning the effective management strategies since the features are varied from place to place.

\section{Funding}

This research did not receive any specific grant from funding agencies in the public, commercial, or not-for-profit sectors.

\section{Ethical approval}

The study was conducted after getting the Institutional ethics committee approval Jubilee Centre for Medical Research (JCMR), Jubilee Mission Medical College \& Research Institute Institutional Ethical Committee Number: 42/21/IEC/JMMC\&RI.

\section{Declaration of competing interest}

The authors declare that they have no competing interests.

\section{Appendix A. Supplementary data}

Supplementary data to this article can be found online at https://doi. org/10.1016/j.cegh.2021.100931.

\section{References}

1 World Health Organization. March 19). "WHO Director-General's Opening Remarks at the Media Briefing on COVID-19"; 2020. Retrieved from https://www.who.int/direct or-general/speeches/detail/who-director-general-s-opening-remarks-at-the-mediabriefing-on-covid-19-11-march-2020.

2 World Health Organization. WHO Coronavirus Disease(COVID-19) Dashboard. January 15; 2021. Available from: https://covid19.who.int/?gclid=EAIaIQobCh MI_PjRivyd7gIVykNgCh2p4gTkEAAYASAAEgLqffD_BwE.

3 Andrews MA, Areekal B, Rajesh KR, et al. First confirmed case of COVID-19 infection in India: a case report. Indian J Med Res. 2020;151(5):490.

4 Ram Venkata S, Babu Giridhara R, Prabhakaran Dorairaj. COVID-19 pandemic in India. Eur Heart J. 2020;41(40):3874-3876.

5 Huang C, Wang Y, Li X, et al. Clinical features of patients infected with 2019 novel coronavirus in Wuhan, China. Lancet. 2020;395(10223):497-506.

6 Joshi J, Mishra P, Kamar SB, et al. Clinical Profile of Cases of COVID-19 in Far Western Province of Nepal. vol. 34. 2020:40, 20.

7 Mohan A, Tiwari P, Bhatnagar S, et al. Clinico-demographic profile \& hospital outcomes of COVID-19 patients admitted at a tertiary care centre in north India. Indian J Med Res. 2020;152(1):61.

8 Soni SL, Kajal K, Yaddanapudi LN, et al. Demographic \& clinical profile of patients with COVID-19 at a tertiary care hospital in north India. Indian J Med Res. 2020;10: 103-111.

9 Zhang JJ, Dong X, Cao YY, et al. Clinical characteristics of 140 patients infected with SARS-CoV-2 in Wuhan, China. Allergy. 2020;75(7):1730-1741.

10 [Internet]. Kerala. Revised Guideline for Testing, Quarantine, Hospital Admission and Discharge for COVID-19 Based on Current Risk Assessment. Health and family welfare department; 2020. Available from: https://dhs.kerala.gov.in/wp-content/uploads/ 2020/03/reg_12032020.pdf.

11 World Health Organization. Respond to COVID-19 - Learning from Kerala; 2020 July 2. Retrieved from https://www.who.int/india/news/feature-stories/detail/respondi ng-to-covid-19-learnings-from-kerala.

12 Nikpouraghdam M, Farahani AJ, Alishiri G, et al. Epidemiological characteristics of coronavirus disease 2019 (COVID-19) patients in Iran: a single center study. J Clin Virol. 2020;127:104378.

13 Sharma R, Daga MK, Mawari G, et al. Global trends of clinical presentation of COVID19. Indian J Med Specialities. 2020;11(2):59.

14 Ma Y, Xu QN, Wang FL, et al. Characteristics of asymptomatic patients with SARSCoV-2 infection in Jinan, China. Microb Infect. 2020;22(4-5):212-217.

15 Zeng F, Huang Y, Guo Y, et al. Association of inflammatory markers with the severity of COVID-19: a meta-analysis. Int J Infect Dis. 2020;96:467-474.

16 Al Mutair A, Alhumaid S, Alhuqbani WN, et al. Clinical, epidemiological, and laboratory characteristics of mild-to-moderate COVID-19 patients in Saudi Arabia: an observational cohort study. Eur J Med Res. 2020 Dec;25(1):1-8.

17 de Souza WM, Buss LF, da Silva Candido D, et al. Epidemiological and clinical characteristics of the COVID-19 epidemic in Brazil. Nat Human Behav. 2020 Aug;4 (8):856-865.

18 Young BE, Ong SW, Kalimuddin S, et al. Epidemiologic features and clinical course of patients infected with SARS-CoV-2 in Singapore. Jama. 2020 Apr 21;323(15): 1488-1494.

19 Saini RK, Saini N, Ram S, et al. COVID-19 associated variations in liver function parameters: a retrospective study. Postgrad Med. 2020:138930. https://doi.org/ 10.1136/postgradmedj-2020-138930. Advance online publication.

20 Kumar A, Kumar P, Dungdung A, Gupta AK, Anurag A, Kumar A. Pattern of liver function and clinical profile in COVID-19: a cross-sectional study of 91 patients. Diabetes \& Metabolic Syndrome: Clin Res Rev. 2020;14(6):1951-1954.

21 Scully EP, Haverfield J, Ursin RL, Tannenbaum C, Klein SL. Considering how biological sex impacts immune responses and COVID-19 outcomes. Nat Rev Immunol. 2020;20:442-447.

22 Feng G, Zheng KI, Yan QQ, et al. COVID-19 and liver dysfunction: current insights and emergent therapeutic strategies. J Clin Transl Hepatol. 2020;8(1):18.

23 Gargaglioni LH, Marques DA. Let's talk about sex in the contesssxt of COVID-19. J Appl Physiol. 2020;128(6):1533-1538.

\section{Acknowledgements}

None. 